Supplement of J. Sens. Sens. Syst., 9, 383-389, 2020

https://doi.org/10.5194/jsss-9-383-2020-supplement

(C) Author(s) 2020. This work is distributed under

the Creative Commons Attribution 4.0 License.

(c) (1)

Supplement of

\title{
Glass electrode half-cells for measuring unified pH in ethanol-water mixtures
}

Agnes Heering et al.

Correspondence to: Frank Bastkowski (frank.bastkowski@ptb.de)

The copyright of individual parts of the supplement might differ from the CC BY 4.0 License. 


\section{Supplement}

B

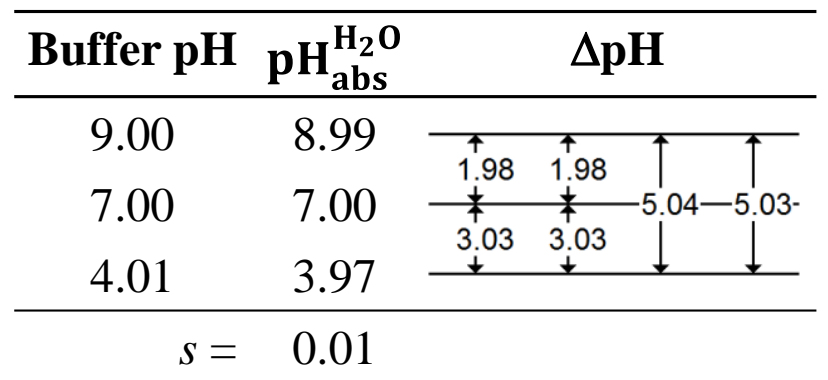

D

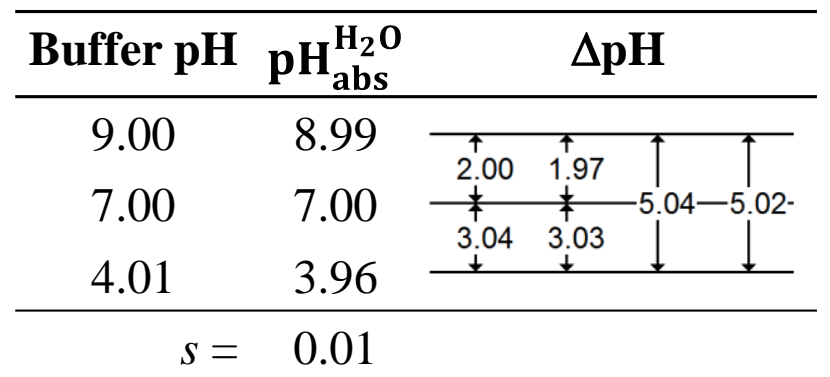

C

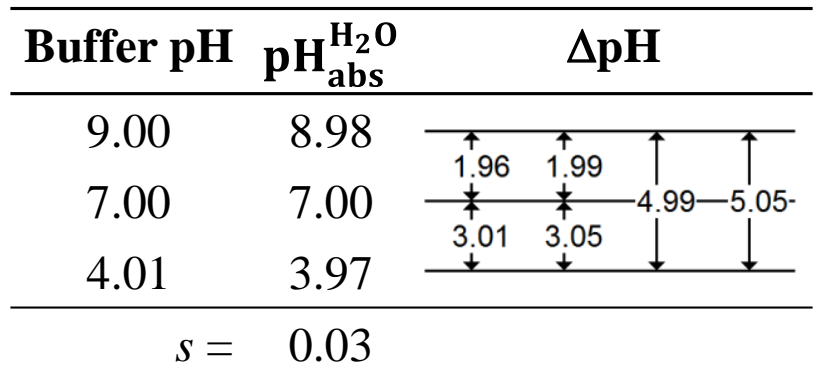

Combined electrodes

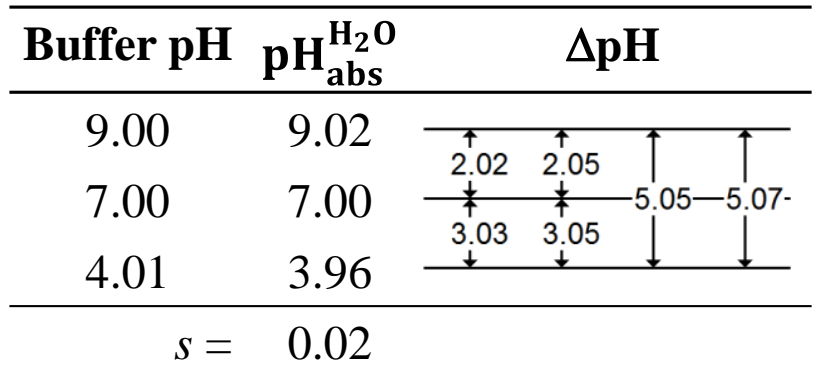

Figure S 1: pH ladder with aqueous standard buffers. Buffer pH 7 was used as an anchor value (see Method section) and [N225][NTf $]$ was used as salt bridge. Measured with a pair of half-cells B, C, D, and combined electrodes. 
A

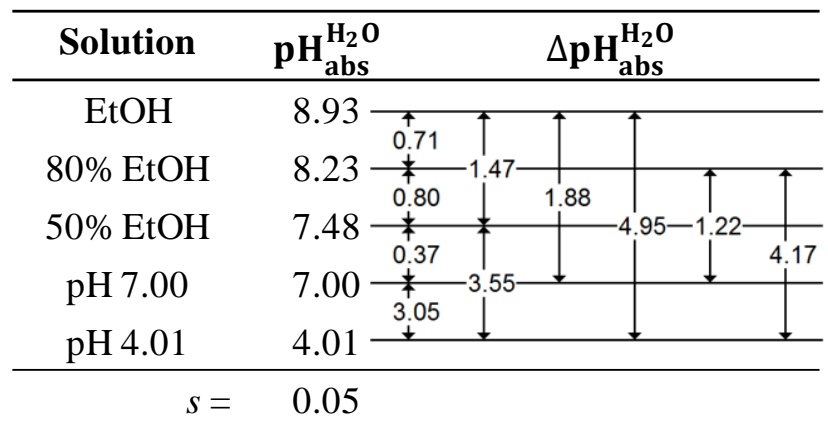

C

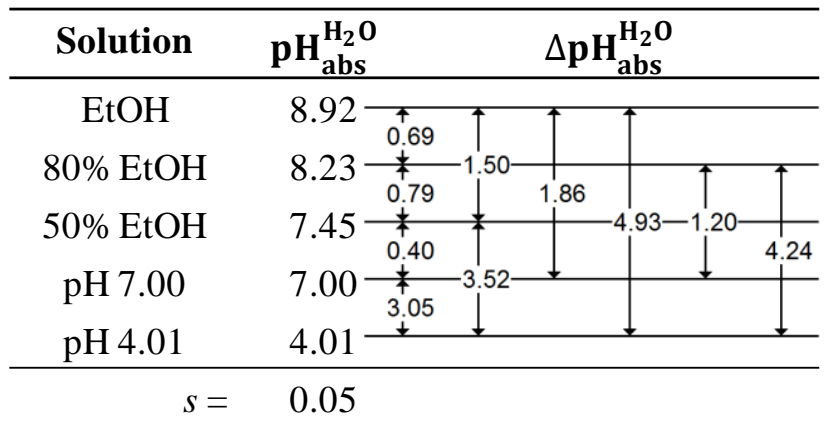

B

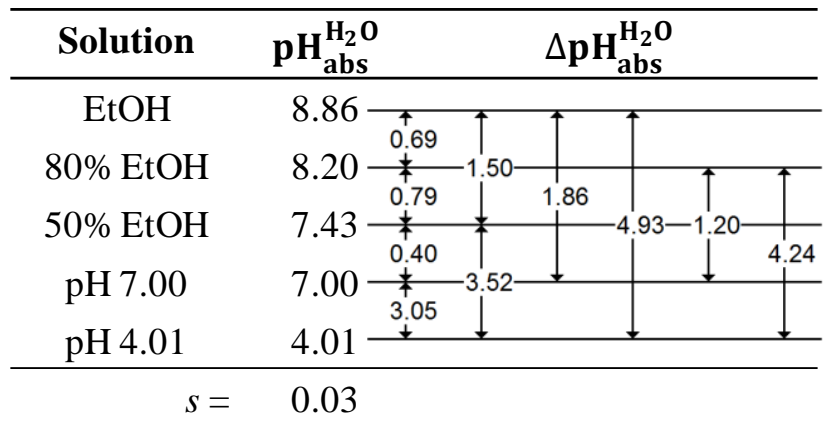

D

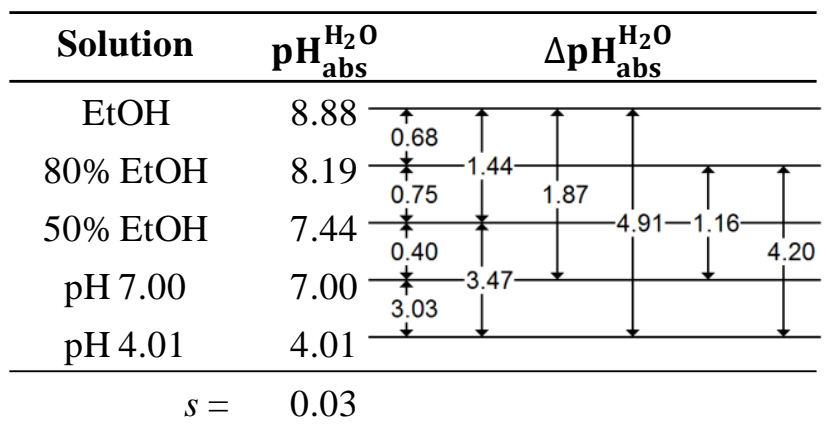

Figure S 2: pH ladder with $10 \mathrm{mM}$ ammonium formate in ethanol-water mixtures. Buffer pH 7 and pH 4 were used as anchor values and $\left[\mathrm{N}_{2225}\right]\left[\mathrm{NTf}_{2}\right]$ was used as salt bridge. Measured with electrode pairs A, B, C and D. 